\title{
The Role of Parenting Style in Instilling Adolescents Pro-social Behavior: The Case of Adolescent Students in Arba-minch, Konso, and Jinka, Southern Ethiopia
}

\author{
Zebene Temtmie*, Demssie Tefera \\ Department of Psychology, School of Behavioral and Pedagogical Science, Arba Minch University, Arba Minch, Ethiopia \\ Email address: \\ zebene.temtmie@amu.edu.et(Z. Temtmie),Zebenet03@gmail.com (Z. Temtmie),demessie.tefera@amu.edu.et(D. Tefera) \\ ${ }^{*}$ Corresponding author
}

To cite this article:

Zebene Temtmie, Demssie Tefera. The Role of Parenting Style in Instilling Adolescents Pro-social Behavior: The Case of Adolescent Students in Arba-minch, Konso, and Jinka, Southern Ethiopia. American Journal of Applied Psychology. Vol. 9, No. 1, 2020, pp. 22-33.

doi: 10.11648/j.ajap.20200901.14

Received: January 4, 2020; Accepted: February 24, 2020; Published: March 17, 2020

\begin{abstract}
The aim of this study is to investigate the role of parenting styles in instilling adolescents' pro-social behavior among secondary and preparatory school students. Two adapted instruments, i.e. the Pro-social Tendencies Measure (Eisenberg et al., 1995, Rushton et al., 1981) and Parental Authority Questionnaire (Buri, 1988) were used. The researchers hypothesized that, perceived Authoritative parenting significantly predicts adolescents' pro-social behavior higher than those who perceive their parents relied primarily on Authoritarian, Permissive, or Neglectful Parenting's, and there is gender difference in pro-social behavior among adolescent students. Adapted Parental authority questionnaires and pro-social tendencies measure were distributed to 392 adolescent students. The study was employed Correlational research design. The data analysis used statistical techniques like bivariate correlation, regression analysis and independent samples t-test. The significant relationship were found between the permissive as well as the authoritative parenting style and the level of adolescents pro-social behavior development, $(\mathrm{P}<0.05)$ at a $(.048)$ and $(\mathrm{P}<0.05)$ at a $(.049)$ level of significance respectively. Regression analysis was performed and the hypothesis was rejected because permissive parenting style was found to have a more powerful impact on development of adolescents pro-social behavior with $(\beta=.132, \mathrm{p}<.05)$. There was no statistically significant gender difference in overall pro-social behavior $\mathrm{t}_{(390)}=.296, \mathrm{p}=.767$. However, there was significant mean difference between male and female adolescent students only in altruism sub-type of pro-social behavior $\mathrm{t}_{(308.128)}=1.541, \mathrm{p}=.017$ (two-tailed); female adolescents were scored higher on mean score of altruism pro-social behavior than male adolescents. Important implications of the results were discussed and recommendations are also forwarded.
\end{abstract}

Keywords: Parenting Styles, Adolescents, Pro-social Behavior

\section{Introduction}

\subsection{Background of the Study}

Adolescence is a period of experiencing an exciting and dynamic change. It is a time of growing up, moving from the immaturity of childhood (physical, cognitive/thinking social etc.) to the maturity of adulthood. As adolescents are faced with changes in their bodies and cognitive development, they are consistently renegotiating their relationship with family, friends, school and community. Ideally, their view of the world expands, and a new orientation to their future as productive independent adults emerges [14].

While these changes and views occur, there is a tendency of adolescents to engage in anti or pro-social behaviors. Different factors can be mentioned as a cause for this. But, researchers believe that their relationship with parents significantly influence on creating preferable behavior in adolescents [16].

One of the positive behaviors that need to be supported by parents is pro-social behavior. Pro-social behaviors are defined as any behaviors that are intended to help or benefit others in need, society as a whole should take an interest in behaviors that positively impact its members $[12,13]$. Studies have demonstrated that those who engage in more pro-social 
behaviors also engage in fewer aggressive and antisocial behaviors, succeed in academics, participate in positive extracurricular activities, and experience more acceptances by their peers $[5,10]$. Empathic individuals who successfully cope with the vicarious negative affect that accompanies understanding others' distressful situations develop sympathy (i.e., compassion) for others. This compassion for others is thought to motivate one to engage in pro-social behavior. If an empathic person fails to cope with such negative feelings, however, the individual may become overwhelmed with feelings of personal distress and focus on relieving their own negative feelings instead of helping others $[10,13]$.

Parenting styles and practices have been found to influence children and adolescents' pro-social behaviors. Harsh or power-assertive discipline, for example, has consistently been found to be negatively related to pro-social behaviors (e.g., [8, 7]. Similarly, socialization theorists witnessed the way in which parents play an important role in promoting and fostering pro-social behaviors in their children and adolescents $[5,14]$. Other scholars determined that the styles parents use in rearing children have an effect on the children's development of pro-social behavior [19].

Theoretical Framework of Parenting Style and its Typologies

Parenting styles refer to a global construct reflecting the parental behaviors and attitudes towards their children and the qualities of interactions and relationships among parents and children and used to categorize parents typologically [3].

Psychologist Diana Baumrind was the first researcher who hypothesized the theoretical model of parenting style. Based on the two aspects of parenting behavior - parental control and parental warmth i.e. the extent to which parents manage their children's behavior from being very controlling to setting few rules and demands was referred to as parental control. Whereas, Parental warmth refers the extent to which parents are accepting and responsive of their children's behavior as opposed to being unresponsive and rejecting [4]. Accordingly, Baumrind categorized parenting style as authoritarian, permissive and authoritative.

Other researchers, analyzed Baumrind's conceptualization of parenting styles and later expanded and revised her typologies [21]. They modified Baumrind's categorization in which parents are classified based on two dimensions. According to [21], the combined effects of the two parental dimensions (warmth/love and control/demandingness) yield four types of families (authoritative, authoritarian, permissive and neglectful) that emphasized in some works [19]

The combination of these dimensions (parental warmth/ love and parental control/demandingness) results in four parenting types as shown below.

Table 1. Parenting types/ styles.

\begin{tabular}{lll}
\hline & Accepting Responsive child centered & Rejecting Unresponsive Parent-centered \\
\hline Demanding / Control & Authoritative & Authoritarian \\
Undemanding / Not controlling & Indulgent & Neglectful \\
\hline
\end{tabular}

Adapted from [22]

It is Dianna Baumrind's seminar work in the area of parenting styles that has directed research on the subject for decades $[3,4,21]$. Baumrind has created the three primary styles of parental interaction and the fourth was developed by Maccoby and Martin. Baumrind, Maccoby and Martin characterize the four types of parenting styles as follows:

Authoritative Parenting Style

Authoritative parenting is a flexible, interactive style characterized by high levels of responsiveness and demandingness [3]. It is characterized by its finest balancing between responsiveness and demandingness; and directing children in a rational, issue-oriented, disciplined manner by clarifying the interpretation behind rules. It is high in all the four dimensions of family functioning [21].

Authoritarian Parenting Style

Authoritarian parenting is a highly restrictive style, in which children are expected to maintain strict obedience to rigid rule systems. These parents are high in demandingness but low in responsiveness [3]. Authoritarian parents constrain their children's independence and they want their children to go after strict parental rules and commands without any question or complaint. If children violate these rules, severe punishment will follow [21].

Permissive (Indulgent) Parenting Style

Permissive parenting is a loosely structured style, in which children are exposed to few parental demands and expectations. Permissive parents are high in responsiveness but low in demandingness. Children are encouraged to express their feelings and impulses. Little restriction is imposed, resulting in minimal overt control over behaviors [3, 4]. Children of permissive parents have been shown to function poorly in all domains, including social and cognitive.

Neglecting or Uninvolved Parenting Style

According to [21], Neglectful parents are inconsistent in setting and maintain age-appropriate standards and expectations for their children and adolescents and in filling their parental responsibilities. Neglectful parenting style is characterized by few demands, low responsibilities and little communication. It is also believed to be the most unfavorable of the four types of parenting styles on children's and adolescents' development [21]

Pro-Social Behavior and its Different Types

Eisenberg, N., \& Fabes have shown different types of pro-social behaviors which are related differently to theoretically related constructs [13].

Based on prior theories and research, four types of pro-social behaviors are identified: altruistic pro-social behaviors, compliant pro-social behaviors, emotional pro-social behaviors, and public pro-social behaviors $[13,15]$. 
On the other hand, Carlo and Randall, proposed six behaviors $[10,11]$. The authors identified the existence of plausible motives underlying the tendency towards a certain type of pro-social behavior which makes the study of pro-social behavior more concrete. The types of pro-social behaviors are defined as follows.

Altruistic Pro-Social Behaviors

Altruistic pro-social behaviors were defined as voluntary helping motivated primarily by concern for the needs and welfare of another, often induced by sympathy responding and internalized norms/principles consistent with helping others [13]. More specifically, altruism requires sacrificing one's own gain in order to promote another's well-being [17].

Compliant Pro-Social Behaviors

Compliant pro-social behaviors were defined as helping others in response to a verbal or nonverbal request [12].

Emotional Pro-Social Behaviors

Emotional pro-social behaviors were conceptualized as an orientation toward helping others under emotionally evocative circumstances. Some helping situations can be characterized as highly emotionally charged. For some individuals, highly emotionally evocative situations are likely to lead to over arousal and personal distress; whereas, for other individuals, the response might be sympathy $[13,15]$.

Public Pro-Social Behaviors

Pro-social behaviors conducted in front of an audience are likely to be motivated, at least in part, by a desire to gain the approval and respect of others (e.g., parents, peers) and increase one's self-worth. This type of behavior is termed as public pro-social behavior [13].

Based on these basic four types of pro-social behaviors, Carlo and Randall added the following two pro-social behaviors (anonymous and dire) based on exploratory factor analyses they conducted in three pilot studies $[10,11]$.

Anonymous Pro-Social Behavior

Anonymous pro-social behaviors were defined as helping performed without the knowledge of whom helped [10].

Dire Pro-Social Behavior

Dire pro-social behaviors were defined as helping in crisis or emergency situations [10].

Few studies on helping behavior had been conducted in Ethiopia. However, they treated the topic with variables different from the current study. All these studies showed the effect or relationship of the parenting dimensions from different behavioral perspectives of adolescents rather than pro-social behavior.

\subsection{Statement of the Problem}

Adolescence is a turbulent time charged with conflict and mood swings. Lam, C. M, Azimpour et al., 2012, described adolescence as a period of enormous opportunities and threats [19]. On the contrary, Lamborn, S., Mounts, N., Steinberg, L., Dornbusch, S., \& Santrock, defines adolescence as the developmental period of transition between childhood and adulthood that involves biological, cognitive and social changes which has positive aspects of human behavior [20]. However, many researches were conducted in relation to the developmental aspects of adolescents give much more emphasis to the negative side of human behaviors like delinquency, aggression, crime and substance abuse, giving little attention to the positive aspects of human behavior.

There is an increasing recognition within developmental and sociological theories that parents are important institution to socialize children and adolescents. According to moral philosophy and some moral psychologists, moral issues like pro-social behavior should be viewed culturally rather than universally. There are some studies conducted in the western and Asian countries in relation to the effects of parenting styles and/or peer pressure over that of pro-social behavior [23].

In Ethiopia, there were researchers who studied pro-social behavior in relation to different variables [26, 27,]. Although others were tried to find out the relationship between parenting styles and academic performance, parenting styles in relation with identity status of adolescents, and parenting styles in relation to Moral development of adolescents, yet none of them have addressed how the role of parenting style affects the development of adolescents pro-social behavior in Ethiopia [7, 22, 24, 30, 28, 29].

Hence, due to cultural differences, the researchers were strike by the fact that there is a lack of research examining the role of parenting styles in instilling pro-social behavior in Ethiopian socio-cultural context. The major concern of this study was, therefore, to investigate the role of parenting styles in the development of pro-social behavior in adolescents among secondary and preparatory school students. Accordingly, the researchers attempt to answer the following basic research questions and corresponding hypotheses were formulated.

1. How do parenting styles (authoritative, authoritarian, permissive and neglectful) are related to pro-social behavior development of adolescents?

2. To what extent dose each style of parenting predict adolescents' pro-social behavior development?

3 . Is there a statistically significant gender difference in pro-social behaviors of adolescents?

Having these questions in hand, the researcher has hypothesized the next hypotheses:

Past research in the western culture has shown that the authoritative parenting style traditionally has been positively correlated to social behaviors of children as well as academic achievement [4], and it is also associated to pro-social behaviors of adolescents [13]

In this study the researcher hypothesize that authoritative parenting is also be positively associated with greater gains in development of adolescents' pro-social behavior.

The two corresponding Researcher's proposed Hypotheses are:

1. The levels of pro-social behavior achieved in the secondary and preparatory school students who perceived that they were parented by parents utilizing an Authoritative parenting style would be significantly higher than Authoritarian, Permissive or Neglectful Parenting Styles. 
2. There is gender difference in pro-social behavior among secondary and preparatory school adolescent students. The Null Hypotheses were as follows:

3. There is no significant relationship between secondary and preparatory school students who perceive their parents utilized an Authoritative parenting style and the levels of pro-social behavior they have achieved.

4. There is no significant relationship between secondary and preparatory school students who perceive their parents utilized an Authoritarian parenting style and the levels of pro-social behavior they have achieved.

5. There is no significant relationship between secondary and preparatory school students who perceive their parents utilized a Permissive parenting style and the levels of pro-social behavior they have achieved.

6. There is no significant relationship between secondary and preparatory school students who perceive their parents utilized a Neglectful parenting style and the levels of pro-social behavior they have achieved.

7. There is no significant gender difference in the developments of pro-social behavior among secondary and preparatory school adolescent students.

\subsection{Objectives of the Study}

The general objective of this study is to investigate the role of parenting styles in the development of pro-social behaviors in adolescents among secondary and preparatory school students. More specifically it attempts to:

1. Examine the relationship between parenting styles (authoritative, authoritarian, neglectful, and indulgent) and development of pro-social behavior of adolescents.

2. Identify the extent to which parenting style best predicts adolescent's development of pro-social behaviors.

3. State whether there exists a significant gender difference in pro-social behaviors of adolescents.

\subsection{Significance of the Study}

This study is expected to have certain values and social contributions. The findings of the study can expand our knowledge of the impact child rearing practice on the development of pro-social behavior in adolescents. This creates a significant question for contemporary parents, educators and counselors to address.

Assisting persons, particularly parents, educators and professional counselors, with the development of solid principles designed to address the issue of pro-social behavior in adolescents. Hence there is a lack of research examining the role of parenting styles for the development of pro-social behaviors of adolescents in Ethiopian context. Therefore this study is salient for Ethiopian parents', counselors', educators', and adolescents'. In addition to this, the study will be used as reference and show directions for further researchers who are interested in the area.

\subsection{Operational Definition of Terms}

Adolescents: refers to students which are found in secondary and preparatory school whose ages were between 14-20 years old.

Instilling: refers to the way of better pushing or increasing adolescent's voluntary helping behavior.

Parenting Style: It refers to the extent to which adolescents' perception of how their parents handling them with respect to parental control and parental warmth as measured by parenting style scale

Pro-social behavior: It is voluntary behavior of adolescent students intended to benefit, sharing or helps another as measured by pro-social tendency measures.

\section{Methods}

\subsection{The Research Design}

The study has employed correlational research design to examine the relationships between parenting style and the development of pro-social behavior of secondary and preparatory adolescent students. Parenting style were independent variables, whereas development of pro-social behaviors of adolescents was the dependent variables.

\subsection{The Study Area}

The site of the study was in the Southern Ethiopian. Particularly the area of the study was Arba Minch, Jinka and Konso towns' secondary and preparatory schools. Its location is southern part of our capital city Addis Ababa around 500-700 kilometers. The rational for selecting the study area is; the issue concerned with the developments of Pro-social behavior is not sufficiently studied in Ethiopia especially among adolescent students and it is obvious that most of the researchers prefer to conduct their studies in the main capital city Addis Ababa because of different factors to go out in other areas.

\subsection{Participants}

The population from which the sample would draw consists of secondary and preparatory government school adolescent students, who are enrolled and were attending in the year of 2018/19 in Arba Minch, Jinka and Konso towns.

\section{Sampling}

Arba Minch town, has two secondary and preparatory schools and one secondary schools; namely Arba Minch and Chamo secondary and preparatory schools and Abaya secondary school. Then, from Arba Minch and Chamo secondary and preparatory schools, eight sections (four sections from chamo secondary and preparatory school i.e., two sections from grade nine, as well as two sections from grade ten, and four sections from preparatory school i.e., two sections from grade eleven and two sections from grade twelve) were randomly selected with lottery method.

Similarly, in konso town, there is one secondary and preparatory school. Whereas, in Jinka town, there are one secondary and preparatory school as well as three secondary schools. Then, from Konso and Jinka secondary and preparatory schools six sections i.e. four from Jinka and two 
from Konso were taken randomly. In addition, form the three Jinka secondary schools one school and two sections from it were randomly selected.

Proportional stratified random sampling was used to take proportional number of students from the population based their sex. The total numbers of students found in the five schools were 4119 (2166 male and 1953 female). Out of 4119 regular students enrolled in the college, a total of 411 (237 male and 155 female) adolescent students were chosen using proportional stratified random sampling based on sex and number of students in each grade levels since, the intention of the researchers are to investigate the difference between male and female subgroups in their pro-social behavior. The sample size was determined based on the recommendation of [19] formula i.e., $10 \%$ of the total population which was used for determining sample size in research activities.

Among the total 411, 19 respondents did not complete the questionnaire appropriately. These were excluded from the analysis. Therefore, the analysis was based on the data obtained from 392 respondents. (See Table 2 below for the details)

Table 2. Distribution of sample size.

\begin{tabular}{|c|c|c|c|c|}
\hline \multirow{2}{*}{ Schools } & \multirow{2}{*}{ Grade } & \multirow{2}{*}{$\begin{array}{l}\text { Population } \\
\text { Numbers }\end{array}$} & \multicolumn{2}{|l|}{ Sample } \\
\hline & & & Numbers & $\%$ \\
\hline Konso General Secondary and preparatory School & $9-12$ & 1110 & 103 & 26.3 \\
\hline Jinka General Secondary and preparatory School \& Jinka high School & $\begin{array}{l}9-12 \\
9-10\end{array}$ & 1208 & 127 & 32.4 \\
\hline Arba \& Chamo General Secondary and preparatory School & $9-12$ & 1801 & 162 & 41.3 \\
\hline Total & & 4119 & 392 & 100 \\
\hline
\end{tabular}

\subsection{Variables of the Study}

Dependent Variable: Pro-social behavior- it was obtained from the instruments that were developed to measure the development of Pro-social behavior in adolescents.

Independent variables: Parenting style- it is students' ratings of their parents in terms of the four categories of parenting style; authoritative, authoritarian, permissive and neglectful.

\subsection{Instruments}

The two sets of items were adapted from the work of previous researchers and consisted of Parental Authority Questionnaire and Pro-social Tendencies Measure. These questionnaires were translated into Amharic; the administration's working language in the study areas.

Demographic Data: Prior to responding to the two scales, the Participants were requested to provide information on their sex, age, and living condition (i.e., with whom they are living).

Parental Authority Questionnaire

The Parental Authority Questionnaire (PAQ), which was designed to measure four distinct parental styles associated with parental authority [9]. It was modified by [20] based on $[27,26]$ revision of [3] parenting style scale. It has been widely used in research studies [6]. This scale has 32 items in which participants asked to rate their parents in terms of the two parenting dimensions. Respondents are asked to indicate how much they agree with or disagree with each statement. A 5-point Likert scale was used to collect data on the students' responses, with scores ranging from strongly disagree (1) to strongly agree (5). In addition, some items were presented in the basis of a three point likert type (Do not try (1), try a little (2) and try a lot (3).

Evidence for the reliability of the PAQ scales was provided by Buri, J. R. (1988), who reported that the internal reliability for the four PAQ scales ranged from a low of .74 to a high of .87 [9]. Test-retest reliability estimates ranged from a low of .77 to a high of .92 . With regard to content validity there was $95 \%$ agreement between 21 evaluators on the categorization of the items.

Pro-Social Tendency Measure

It is a measure of adolescents' voluntary helping behavior which has six types.

Items for the Pro-social Tendencies Measure (PTM) were selected from previously developed pro-social disposition and behavior scales [12]. The 23-item version of the PTM was composed of 6 sub-scales: public ( 4 items, Cronbach's $\alpha$ $=0.78$ ), anonymous ( 5 items, Cronbach's $\alpha=0.85)$, dire ( 3 items, Cronbach's $\alpha=0.63$ ), emotional (4 items, Cronbach's $\alpha=0.75)$, compliant (2 items, Cronbach's $\alpha=0.80$ ), and altruism (5 items, Cronbach's $\alpha=0.74)$. Participants were asked to rate the extent to which statements described themselves on a point scale ranging from 1 (does not describe me at all) to 5 (describes me greatly).

\subsection{Procedures}

\subsubsection{Instrument Validation and Reliability Computation Procedure}

To test and improve the instruments clarity, a pilot study was conducted in the study site. At the end of the pilot study, issues of clarity of the questions, skipping pattern and sensitivity of the question was assessed and reliability and validity of the scale were computed.

Previous studies in the Ethiopian context have reported reliabilities in terms of warmth/love and control/demandingness scales of PAQ were alpha 0.83 and 0.81 [22], and 0.88 and 0.86 [1], for parental warmth/love and control/demandingness scales respectively. In this study, reliabilities of alpha 0.83 in the upper and 0.80 in in the lower for the parenting style scales administered to students were obtained. Moreover, the pro-social tendency measures were tested. The Cronbach alpha reliability for pro-social subscales compared with those obtained in the main study and other previous studies are presented in Table 3 below. 
Table 3. Coefficients of reliability for pro-social sub scales (Chronbach alpha values).

\begin{tabular}{llllll}
\hline & Pilot study & Main study & $\begin{array}{l}\text { Carlo and } \\
\text { Brandy* }\end{array}$ & Abel Solomon** & $\begin{array}{l}\text { Tsehay and } \\
\text { colleague*** }\end{array}$ \\
\hline Altruism & 0.684 & 0.782 & 0.74 & 0.791 & 0.60 \\
colleague **** & 0.643 \\
Public & 0.824 & 0.892 & 0.78 & 0.899 & 0.83 \\
Emotional & 0.789 & 0.827 & 0.75 & 0.737 & 0.64 \\
Dire & 0.634 & 0.814 & 0.63 & 0.727 & 0.64 \\
Compliant & 0.678 & 0.740 & 0.80 & 0.740 & 0.76 \\
Anonymous & 0.789 & 0.817 & 0.85 & 0.829 & 0.771 \\
\hline
\end{tabular}

Note. $*[10] * *[28][27] * * * *[20]$.

\subsubsection{Data Collection Procedures}

Discussion was held with trained assistant data collectors on how to handle questions that may be raised from respondents. In addition, the researcher arranged conditions to make participants feel free while giving responses with the help of administrative officials and instructors. The researchers with assistant data collectors were described the purpose of the research, how to fill the questionnaire, the voluntary nature of participation, planned uses for the study and the provision for absolute confidentiality of the participants.

\subsubsection{Scoring Procedure}

After all results of the questionnaires were obtained, the data was coded and classifying in to different groups based on responses. Items negatively written were reversely coded. Then after, responses from the items were properly coded and filtered to make ready for statistical processing. Every item was scored for each respondent since an average variable score each individual was determined by average item scores.

\subsubsection{Data Analysis Procedure}

To analyze the data, descriptive and inferential statistics are employed. To summarize the raw data, descriptive statistics such as frequency, percentage, mean, and standard deviation were computed. Then, to examine the correlation among independent and dependent variables inter-correlations were computed by using Pearson r. To know which parenting style is the most predictor for the development of pro-social behavior in adolescents, regression analysis was employed. Finally, Independent sample t-test was used to analyze gender differences in the overall pro-social behavior as well as in the sub types mean score. Before proceeding with the actual statistical analysis, assumptions associated with the use of each of the analysis were checked. Consequently, the complete quantitative data were analyzed using statistical package for social science (SPSS version 21).

\section{Results}

In this study, the researchers have presented the major findings and results of the statistical analysis. Among 392 participants, more than half $(237,60.5 \%)$ were male students while the rest $(155,39.5 \%)$ were female. The participants age ranges are from 15-20 years. The analysis was done based on three major research questions/objectives

1. How do parenting styles (authoritative, authoritarian, permissive and neglectful) are related to pro-social behavior development of adolescents?

2. To what extent dose each style of parenting predict adolescents' pro-social behavior development?

3 . Is there a statistically significant gender difference in pro-social behaviors of adolescents?

\subsection{Interrelation Among the Study Variables}

Table 4. Interrelation among the study variables.

\begin{tabular}{|c|c|c|c|c|c|c|c|c|c|c|c|c|}
\hline Variables & & 1 & 2 & 3 & 4 & 5 & 6 & 7 & 8 & 9 & 10 & 11 \\
\hline Authoritative & $\begin{array}{l}\text { correlation } \\
\text { sig(2-tailed })\end{array}$ & 1 & & & & & & & & & & \\
\hline Permissive & $\begin{array}{l}\text { correlation } \\
\text { sig(2-tailed) }\end{array}$ & $\begin{array}{l}.662 * * \\
.015\end{array}$ & 1 & & & & & & & & & \\
\hline Authoritarian & $\begin{array}{l}\text { correlation } \\
\text { sig(2-tailed) }\end{array}$ & $\begin{array}{l}-.506^{* *} \\
.043\end{array}$ & $\begin{array}{l}.501 \\
.087\end{array}$ & 1 & & & & & & & & \\
\hline Neglectful & $\begin{array}{l}\text { correlation } \\
\text { sig(2-tailed) }\end{array}$ & $\begin{array}{l}-.526 * * \\
.047\end{array}$ & $\begin{array}{l}.527 \\
.078\end{array}$ & $\begin{array}{l}.703 * * \\
.023\end{array}$ & 1 & & & & & & & \\
\hline Public & $\begin{array}{l}\text { correlation } \\
\text { sig(2-tailed) }\end{array}$ & $\begin{array}{l}.243 \\
.049\end{array}$ & $\begin{array}{l}.038 \\
.068\end{array}$ & $\begin{array}{l}.285 \\
.078\end{array}$ & $\begin{array}{l}.297 \\
.082\end{array}$ & 1 & & & & & & \\
\hline Compliant & $\begin{array}{l}\text { correlation } \\
\text { sig(2-tailed) }\end{array}$ & $\begin{array}{l}.164 \\
.053\end{array}$ & $\begin{array}{l}.243 \\
.064\end{array}$ & $\begin{array}{l}.284 \\
.065\end{array}$ & $\begin{array}{l}.278 \\
.054\end{array}$ & $\begin{array}{l}.533 * * \\
.043\end{array}$ & 1 & & & & & \\
\hline Emotional & $\begin{array}{l}\text { correlation } \\
\text { sig(2-tailed) }\end{array}$ & $\begin{array}{l}.257 \\
.065\end{array}$ & $\begin{array}{l}.265 \\
.067\end{array}$ & $\begin{array}{l}.323 \\
.047\end{array}$ & $\begin{array}{l}.279 \\
.089\end{array}$ & $\begin{array}{l}.644 \\
.031\end{array}$ & $\begin{array}{l}.645 \\
.000\end{array}$ & 1 & & & & \\
\hline Dire & $\begin{array}{l}\text { correlation } \\
\text { sig(2-tailed) }\end{array}$ & $\begin{array}{l}.221 \\
.036 \\
\end{array}$ & $\begin{array}{l}.253 \\
.025 \\
\end{array}$ & $\begin{array}{l}.251 \\
.213 \\
\end{array}$ & $\begin{array}{l}.285 \\
.432 \\
\end{array}$ & $\begin{array}{l}.597 \\
.045 \\
\end{array}$ & $\begin{array}{l}.634 \\
.089 \\
\end{array}$ & $\begin{array}{l}.697^{* *} * \\
.003\end{array}$ & 1 & & & \\
\hline
\end{tabular}




\begin{tabular}{|c|c|c|c|c|c|c|c|c|c|c|c|c|}
\hline Variables & & 1 & 2 & 3 & 4 & 5 & 6 & 7 & 8 & 9 & 10 & 11 \\
\hline \multirow{2}{*}{ Anonymous } & correlation & .177 & .260 & .291 & .270 & .574 & .565 & .682 & .662 & \multirow{2}{*}{1} & & \\
\hline & sig(2-tailed) & .065 & .057 & .078 & .038 & .003 & .087 & .065 & .046 & & & \\
\hline \multirow{2}{*}{ Altruisms } & correlation & $155^{*}$ & $.189 *$ & -.214 & $-.257 * *$ & $-.442 * *$ & $-.393 * *$ & -.506 & -.457 & -.565 & \multirow{2}{*}{1} & \\
\hline & $\operatorname{sig}(2$-tailed) & .046 & .043 & .054 & .048 & .014 & .004 & .067 & .049 & .037 & & \\
\hline \multirow{2}{*}{ Total Pro-social } & correlation & $.243 * *$ & $.282 * *$ & .323 & $-.297 * *$ & $.795 * *$ & $.741 * *$ & $.841 * *$ & $.815^{* *}$ & $.797 * *$ & $-.310 * *$ & \multirow{2}{*}{1} \\
\hline & sig(2-tailed) & .048 & .021 & .847 & .043 & .036 & .038 & .041 & .032 & .029 & .037 & \\
\hline
\end{tabular}

Note. Note. *. Correlation is significant at the 0.05 level (2-tailed).

$* *$. Correlation is significant at the 0.01 level (2-tailed).

Bivariate correlations were computed to examine the interrelations among the study variables (i.e., parenting styles, and adolescents' pro-social behaviors) (see Table 4). Significant results are summarized as follows:

1. Authoritative parenting style was significantly and positively correlated with Permissive parenting style $(r=.662$, at a (.015) level of significance and negatively correlated with authoritarian and neglectful parenting style $(\mathrm{r}=-.506$, at a $(.043)$ and -.526 , at a $(.047)$ respectively.

2. Authoritarian parenting style was significantly and positively correlated with neglectful parenting style $(\mathrm{r}=.703$, at a $(.023)$ level of significance.

3. The public pro-social behavior was significantly correlated with the compliant pro-social behavior $(\mathrm{r}=.533$ at a $(.043)$, and it was also significantly and negatively correlated with altruistic pro-social behavior $(\mathrm{r}=-.442$ at a $(.014)$ level of significance.

4. The emotional pro-social behavior was positively and significantly correlated with the dire $(r=.697$ at a $(.003)$ level of significance.
5. The altruism pro-social behavior was negatively and significantly correlated with the compliant pro-social behaviors $(\mathrm{r}=-.393$, at a (.004) level of significance, and was positively and significantly correlated with that of the authoritative parenting style $(\mathrm{r}=.155$, at a $(.046)$ and permissive parenting style $(\mathrm{r}=.189$ at a $(.043)$ level of significance. On the other hand, it was also significantly and negatively correlated with neglectful parenting styles $(r=-.257$ at a $(.048)$ level of significance.

6 . The overall pro-social behavior was positively and significantly correlated with all sub types of pro-social behavior except altruistic sub types (public, $r=.795$ at a (.036), compliant, $\mathrm{r}=.741$ at a (.038), emotional, $\mathrm{r}=.841$ at a (.041), dire, $\mathrm{r}=.815$ at a (.032), and autonomous, $\mathrm{r}$ $=.797$ at a (.029) levels of significance respectively. It was negatively and significantly correlated with the altruistic sub type $(\mathrm{r}=-.310$ at a (.037) levels of significance.

Regression Analysis of the Four Types of Parenting Style Scores and Pro-Social Tendency Measure Score among Secondary and Preparatory School Adolescents

Table 5. Regression analysis of parenting style scores and development of Pro-social tendency measure (a).

Coefficients $^{a}$

\begin{tabular}{|c|c|c|c|c|c|c|}
\hline \multirow{2}{*}{\multicolumn{2}{|c|}{ Model }} & \multicolumn{2}{|c|}{ Unstandardized Coefficients } & \multirow{2}{*}{$\begin{array}{l}\text { Standardized Coefficients } \\
\text { Beta }\end{array}$} & \multirow{2}{*}{$\mathbf{T}$} & \multirow{2}{*}{ Sig. } \\
\hline & & B & Std. Error & & & \\
\hline \multirow{5}{*}{1} & (Constant) & 52.208 & 3.835 & & 13.613 & .000 \\
\hline & Authoritative & .712 & .263 & .127 & 2.705 & .049 \\
\hline & permissive & .256 & .129 & .132 & 1.988 & .048 \\
\hline & Authoritarian & .029 & .138 & .014 & .208 & .836 \\
\hline & neglectful & .297 & .234 & .089 & 1.267 & .206 \\
\hline
\end{tabular}

Dependent Variable: Total measures of pro-social tendency

A regression analysis was run using measures of pro-social tendency score as the dependent measure and the parenting style scores as the independent measures (Table 5). This analysis supported the correlation results with an interesting exception. The regression analysis yielded a Beta Coefficient of .132 for the permissive parenting style with a significance level of .048 . In addition to this, the regression analysis yielded a Beta Coefficient of .127 for the authoritative parenting style with a significance level of .049 .

Table 6. Model Summary of dependent and independent variable scores.

Model Summary ${ }^{b}$

\begin{tabular}{llll}
\hline \multirow{2}{*}{ Model } & R & R Square & Adjusted \\
\cline { 3 - 4 } & & R Square & .118 \\
\hline 1 & $.357 \mathrm{a}$ & .127 & Std. Error of the Estimate \\
\hline
\end{tabular}

a. Predictors: (Constant), Neglectful, Authoritative, Permissive, Authoritarian

b. Dependent Variable: Total measures of pro-social tendency 
Table 7. Summary of multiple regression of predicting pro-social behavior development scores from the independent variable scores of parenting styles.

\begin{tabular}{lllllll}
\hline Model & & Sum of Squares & Df & Mean Squares & F & Sig. \\
\hline 1 & Regression & 7429.370 & 4 & 1857.343 & 14.120 & $.000 \mathrm{~b}$ \\
& Residual & 50904.750 & 387 & 131.537 & & \\
& Total & 58334.120 & 391 & & & \\
\hline
\end{tabular}

a. Dependent Variable: Total measures of pro-social tendency

b. Predictors: (Constant), Neglectful, Authoritative, Permissive, Authoritarian

A regression was calculated predicting subject's development of pro-social behavior based on their perceived parenting style. A significant regression was found $(\mathrm{F}$ $(14.120),=\mathrm{p}<.05)$, with an adjusted $\mathrm{R}^{2}$ of .118 . Additionally, a regression was calculated for each of the groups of subjects who reported an experience of parenting with parents who utilized either a Neglectful, permissive, authoritarian, or authoritative parenting style. The regression analysis revealed that the highest level of relationship between parenting style and development of pro-social behavior achieved was found in the group that reported experiencing the permissive parenting style (Beta Coefficient for this group was .132 and was significant at the .048 level). The Beta Coefficient for the group that perceived that they were parented by parents utilizing the authoritative style was .127 and was significant at the .049 level.

Findings Related to the Hypothesis

The Hypothesis was stated as: The development of pro-social behavior found in adolescent students who perceive that they were parented by parents utilizing an Authoritative parenting style is significantly higher than the levels found in adolescent students who perceive their parents relied primarily on Authoritarian, Neglectful, or Permissive Parenting Styles and there is gender difference in pro-social behavior among adolescents.

The first hypothesis was rejected following a regression analysis which yielded a Beta Coefficient of .132 for the effect of the permissive parenting style on the dependent measure of pro-social behavior. This effect was significant at a .048 level as indicated. The regression analysis also yielded a Beta Coefficient of .127 for the effect of the authoritative parenting style on the dependent measure of pro-social behavior. Even though significant, these results required the rejection of the hypothesis and the rejection of the N1 and N3 Null Hypotheses.

The hypothesis that the authoritative parenting style would yield a stronger effect than either the permissive, neglectful or authoritarian parenting styles was therefore rejected. The parenting style responsible for the most powerful effect on pro-social behavior development discovered as a consequence of regression analysis was for respondents who perceived that they were parented by parents utilizing the permissive parenting style. This indicated that the permissive parenting style accounted for the greatest effect on the pro-social behavior development score. The second hypothesis was also rejected since no statistically significant gender difference in overall pro-social behavior is observed $(\mathrm{t}$ $\left.{ }_{(390)}=0.296, \mathrm{p}>0.05\right)$.

The Null Hypotheses were as follows: There is no significant relationship between secondary and preparatory school adolescents who perceive their parents utilized an Authoritative parenting style (Null $\mathrm{H}$ : 1), authoritarian parenting style (Null H: 2), Permissive parenting style (Null $\mathrm{H}$ : 3), neglectful parenting style (Null $\mathrm{H}: 4$ ), and the levels of pro-social behavior development achieved by these students.

This first null hypothesis was rejected following a regression analysis which yielded a Beta Coefficient of .127 and a significance level of .049 (Table 5) above. The results indicated that the authoritative parenting style accounted for level of development of pro-social behavior achieved by these students at a level that was significant. The second null hypothesis was accepted following a regression analysis which yielded a Beta Coefficient of .014 and a significance level of .836 (Table 5) above. These results indicated that the authoritarian parenting style did not account for a level of change in the respondents' pro-social behavior development score that was significant at the .05 level of significance. On the other hand null hypothesis 3 was rejected following a regression analysis which yielded a Beta Coefficient of .132 and a significance level of .048 as it was indicated above (Table 5) above. The results indicated that there was a significant relationship between secondary and preparatory school adolescents who perceived their parents utilized a Permissive parenting style and the levels of developments of pro-social behavior achieved by these students. The 4 null hypothesis was accepted following a regression analysis which yielded a Beta Coefficient of .089 and a significance level of .206 (Table 5) above. These results indicated that the neglectful parenting style did not account for a level of change in the respondents developments of pro-social behavior score that was significant at the .05 level of significance.

\subsection{Gender Difference in Pro-Social Behavior}

Table 8. Gender difference on overall and sub types of pro-social behavior.

\begin{tabular}{|c|c|c|c|c|c|c|c|c|}
\hline Group & & $\mathbf{N}$ & M & SD & $M$ diff & $\mathbf{T}$ & df & $\mathbf{P}$ \\
\hline \multirow{2}{*}{ Public } & Male & 237 & 15.14 & 4.263 & \multirow{2}{*}{.245} & \multirow{2}{*}{.587} & \multirow{2}{*}{390} & \multirow{2}{*}{.557} \\
\hline & Female & 155 & 14.89 & 3.650 & & & & \\
\hline \multirow{2}{*}{ Compliant } & Male & 237 & 7.54 & 1.963 & \multirow{2}{*}{-.006} & \multirow{2}{*}{-.029} & \multirow{2}{*}{390} & \multirow{2}{*}{.977} \\
\hline & Female & 155 & 7.54 & 2.068 & & & & \\
\hline
\end{tabular}




\begin{tabular}{lllllllll}
\hline Group & & N & M & SD & M diff & T & df & P \\
\hline \multirow{2}{*}{ Emotional } & Male & 237 & 15.61 & 3.435 & .201 & .542 & 390 & .588 \\
& Female & 155 & 15.41 & 3.825 & & & \\
Dire & Male & 237 & 11.05 & 2.772 & .064 & .216 & 390 & .829 \\
& Female & 155 & 10.99 & 2.959 & & & \\
\multirow{2}{*}{ Anonymous } & Male & 237 & 18.61 & 4.284 & .588 & 1.275 & 390 & .203 \\
\multirow{2}{*}{ Altruism } & Female & 155 & 18.02 & 4.734 & & & \\
\multirow{2}{*}{ Overall pro-social } & Male & 237 & 11.61 & 4.258 & -.717 & -1.570 & 390 & .017 \\
& Female & 155 & 12.33 & 4.660 & & & \\
\end{tabular}

Note. $* \mathrm{p}<0.05$

The results of independent sample t-test indicated that, there was no statistically significant mean difference $\mathrm{t}(390)$ $=0.296, p=.767$ ) between female and male adolescents on the overall pro-social behavior. In addition to the overall pro-social behavior, there was no statistically significant mean difference in each of the six measures of development of pro-social behaviors except altruism sub-type in both male and female adolescents. As can be seen from table 8 above, the only significant mean difference between male and female adolescent students was existed for altruism pro-social behavior $\mathrm{t}(308.128)=1.541, \mathrm{p}=.017$. Female adolescents scored higher on mean score of altruism pro-social behavior $(M=12.33)$ than male adolescents $(M=$ 11.61).

The mean score of compliant pro-social behavior for male and female adolescents are equal $(\mathrm{M}=7.54)$. The mean score of adolescent boys for the rest 4 types of pro-social behavior (public, emotional, dire, autonomous) and the over all types of pro-social behavior is greater than mean score of adolescent girls' pro-social behavior. However, these mean differences do not give guarantee for the existence of statistically significant mean difference between adolescent boys and girls development of pro-social behavior.

\section{Discussion}

The purpose of this study was to know how developments of pro-social behavior of adolescents are influenced by their parents' child rearing practices. The discussion has done in line with the basic research questions and hypothesis stated earlier.

Standing from the researchers' findings, the hypothesis produced no statistical significance as were stated and was therefore rejected. The Null hypotheses one and three were also rejected. Null hypothesis number two and four were accepted as stated before. The positive significant relationship were found between the permissive parenting style with the development of overall pro-social behavior achieved $(\mathrm{P}<0.05)$ at a (.021) level of significance. Moreover, authoritative parenting style was positively and significantly related with the development of overall pro-social behavior achieved $(\mathrm{P}<0.05)$ at a (.048) level of significance. On the other hand, overall pro-social behavior was significantly and negatively correlated with neglectful parenting styles $(\mathrm{P}<0.05)$ at a $(.043)$ level of significance.

\subsection{Relationships Between Parenting Styles and Adolescents Development of Pro-social Behavior}

A Correlation matrix was conducted between the parental preferences and the pro-social behavior scores in the result section (Table 4) above. The positive significant relationship were found between the permissive parenting style with the development of overall pro-social behavior achieved $(\mathrm{P}<0.05)$ at a (.021) level of significance. Moreover, authoritative parenting style was positively and significantly related with the development of overall pro-social behavior achieved $(\mathrm{P}<0.05)$ at a $(.048)$ level of significance. On the other hand, overall pro-social behavior was significantly and negatively correlated with neglectful parenting styles $(\mathrm{P}<0.05)$ at a $(.043)$ level of significance (Table 4) above. The parenting style responsible for the most powerful effect on overall pro-social behavior development discovered as a consequence of regression analysis was for respondents who perceived that they were parented by parents utilizing the permissive parenting style (Table 5) above.

These studies have contributed consistent evidence that parenting plays an important role in enhancing or justifying best possible developmental outcomes in children and adolescents. Eisenberg and Fabes did a lot of researches in relation to pro-social behavior and parenting; they found that qualities of social interactions with parents have been linked to displays of pro-social behavior [13]. Their finding was consistent with the present study since permissive and authoritative parenting style had significant impact on adolescent boys' and girls' development of pro-social behavior.

In this study, a regression analysis indicates the permissive and authoritative parenting style on development of pro-social behavior was positively significant. It is partly consistent with research studies examined in the review of the literature on parenting styles; the authoritative parenting style is positively correlated to social behaviors of children [4]. On the other hand, the present finding contradicts with other findings; Tsehay, D. S., Mulatie, M. W., Sellakumar, G. K., \& Begashaw, G. A., Abel, S., they were reported that, there was observed no significant mean difference in pro-social behavior among students experiencing different parenting styles at home [27].

Moreover, Tafetu, S. argued that there was no significant relationship between parenting modeling and helping 
behavior; however, her research was conducted in Ethiopian Red Cross Society [26]. Since the result of the current finding indicates that the permissive and authoritative parenting styles has a significant relationship between parenting styles and adolescents development of pro-social behavior, [26] findings are not also consistent with the present finding.

The present study is showed somewhat consistency since it investigates the influences of parenting styles particularly permissive and authoritative parenting practices has direct relationship for adolescents development of pro-social behavior, with Scott M. H. (2005) finding that pro-social behavior and morality in children and adolescent develops as a result of parental interaction, balanced parenting styles, and a child's own choices [25].

In general, something must be said for the permissive parenting. Its effect on development of pro-social behavior was significant. Something may also be said for authoritative parenting style when it is utilized on a foundation of affirming love.

The researchers believe that the results of this study should encourage through further investigation into the relationship between parenting styles and development of pro-social behavior. There are numerous variables which could have influenced the veracity of the present study. It seems that something other than parenting style is also at work in the pro-social behavior development of adolescents. Generally the scarcity of research concerning the impact that parenting style has on the development of pro-social behavior in secondary and preparatory age adolescents, further research is necessary to determine whether or not there is a statistically significant relationship between parenting style and the development of pro-social behavior in adolescents by considering technological advancements in the twenty-first century, cultural, economic and social influences.

\subsection{Pro-Social Behavior Among Adolescents}

The altruism pro-social behavior was negatively and significantly correlated with public pro-social behavior $(\mathrm{r}=$ -.442 at a (.014) level of significance. This finding is supported with, Carlo, G., \& Rndall, B. A. (2002), assertion that, one may expect a negative correlation between public and altruism pro-social behavior dimensions [10]. The reason can be those adolescents who engage frequently in altruistic pro-social behavior might not be motivated by different or additional concerns like adolescents who tend to be more pro-social in public settings [10]. The current finding was also consistent with other researchers; who showed negative and significant correlation between public and altruism pro-social behaviors [27].

On the other hand, [27] altruism pro-social behavior was negatively related to all pro-social sub-types, except anonymous, was contradicted with the current finding which showed altruistic pro-social behavior was significantly and negatively correlated with public pro-social behavior $(r=-.442$ at a (.014) and with the compliant pro-social behaviors ( $\mathrm{r}=$ -.393 , at a (.004) level of significance.

There was another significant positive correlation between public and compliant pro-social behaviors $(\mathrm{r}=.533$, at a (.043) which was not reported by previous researchers (for example, [10]. But it was consistent with [27] who was found a significant relationship between public and compliant pro-social behaviors among adolescent boys and girls.

\subsection{Gender Differences in Pro-Social Behavior}

The current study showed that, there was no significant mean difference between male and female adolescent students regarding the overall pro-social behavior development $(390)$ $=.296, \mathrm{p}=.767)$. Similarly, Hastings and colleague found no gender difference between boys and girls in there pro-social behavior [17]. Other previous researches also did not show sex difference in levels of overall pro-social behavior between males and females [27]. However, the present finding is contradicted with a study by Tafetu, S. (2007) who showed that, there was significant mean difference in pro-social behavior between male and female students that female students scored more on overall pro-social behavior than male students [26]. This might be explained as a result of females being more socialized to be nurturing and caring in interpersonal relationship.

In addition to the overall pro-social behavior, there was no statistically significant mean difference in each of the six measures of development of pro-social behaviors except for altruism pro-social behavior in both male and female adolescents in our finding. The result of this study showed that, the only statistically significant gender difference was found in the altruism pro-social behavior $t_{(308.128)}=1.541, \mathrm{p}=.017$ between male and female adolescent students. This finding was consistent with other findings like, [2] showed a significant gender difference in pro-social behavior, female were more altruistic than males.

Contrary to this current finding, several interesting gender differences were emerged from previous studies. Adolescent girls scored higher than adolescent boys on altruistic, anonymous, compliant, and emotional types of pro-social behaviors [21]. Furthermore, other researchers have shown that adolescent boys are more concerned with gaining others' approval than adolescent girls [10].

Female students reported greater involvement in emotional, altruism, anonymous and public pro-social behaviors [27]. Similarly, Carlo and colleague reported that female adolescents show more public and emotional pro-social behaviors as compared to male adolescents [10]. Conversely, Carlo, G., \& Rndall, B. A. (2002), reported that male adolescents tend to engage in public forms of pro-social behavior than did adolescent girls [10]. In addition, Carlo and Randall provided evidence of gender differences in pro-social behavior in late adolescents [10]. More specifically, their study found that adolescent girls scored higher than adolescent boys on altruistic, anonymous, compliant, and emotional types of pro social behaviors.

In general, the result obtained in relation to differences on pro-social behavior among male and female adolescents, biological predispositions, experience of socialization 
adopted from parents and peers, received gender-typed expectations from the media, and other conveyers of cultural norms, Hastings, P. D., Utendale, W., T, \& Sullivan, C. (2007) can be put as underlining reasons [17].

\section{Conclusion}

Based on the findings indicated above, the researcher draws the following conclusions, and their corresponding implications:

The result of the present study revealed that there was a significant relationship between the permissive and authoritative parenting style and the development of pro-social behavior in the adolescents. The permissive style actually had a more powerful influence on the respondents' level of pro-social behavior development achieved. It was found out that authoritarian parenting style did not create a significant effect on levels of pro-social behavior achieved by respondents. To the contrary, the result revealed that neglectful parenting style was negatively and significantly correlated with levels of pro-social behavior achieved. Hence, parents also aware the side effects of authoritarian and neglectful parenting practice on the development of pro-social behavior of adolescents.

There was no statistically significant mean difference between male and female adolescents of the Arba minch, Konso and Jinka town high school and preparatory school students in their overall pro-social behavior. But, a statistically significant mean difference was obtained only for altruism sub-types of pro-social behavior. This finding implies that adolescent girl might be most likely to engage in altruism pro-social behavior than adolescent boys.

\section{Recommendations}

Based on the results obtained and the conclusions made above, the researchers forward the following recommendations.

1. The first recommendation is that, the parents and guardians would be permissive and authoritative in their child- rearing practice since the finding indicates positive impact on pro-social behavior in their adolescents. School psychologists, religious leaders, media personnel's and non- governmental organizations which works on child and adolescent development should do their best to teach adolescents parents that they should love and support their adolescents since it has significant effect on the development of pro-social behavior.

2. A second recommendation is that instruments be identified/developed that might be better suited for the language and styles of contemporary adolescents by researchers.

3. A final recommendation is that, the researchers believe that more studies need to be conducted and the analysis be replicated with other interested researchers in Ethiopia based on other independent social variables, like siblings, peer influence, teachers, age, Culture, religion and time spent with media/technologies like video games, internet, and cell phones in relation to their effect on pro-social behavior.

\section{Acknowledgements}

We would like to acknowledge all study participants of the three town adolescent students for their voluntary participation in this study. We also thank those school directors and data collectors' for their invaluable support during data collection. We would like to extend our gratitude to Arba Minch University for all the support and opportunity provided for us to conduct this study.

\section{Conflict of Interest}

The authors declare that they have no competing interests.

\section{References}

[1] Abesha, A. (2012). Effects of parenting styles, academic self-efficacy, and achievement motivation on the academic achievement of university students in Ethiopia. Unpublished dissertation. Perth. Western Australia.

[2] Argaw, B. (2001). The altruistic behavior of home reared, institutionalized and street children. Unpublished Master's Thesis. Addis Ababa University.

[3] Baumrind, D. (1966). Effects of authoritative parental control on child behavior. Child Development. 37, 887-907.

[4] Baumrind, D. (1971). Current patterns of parental authority. Developmental Psychology Monographs. 4 (1, Pt. 2).

[5] Bandura, A. (1986). Social foundations of thought and action: A social cognitive theory. Englewood Cliffs, NJ: Prentice-Hall

[6] Baumrind, D. (1991). The influence of parenting style on adolescent competence and substance abuse. Journal of Early Adolescence, 11, 56-95.144 JOURNAL OF EARLY ADOLESCENCE / MAY 1999

[7] Berhanu, A. (1996). The relationship of parenting styles with academic achievement among senior secondary school students with particular reference to the Kaffecho Zone. Unpublished Masters Thesis. Addis Ababa University.

[8] Boehnke, K., Silbereisen, R. K., Eisenberg, N., Reykowski, J., \& Palmonari, A. (1989). Developmental pattern of pro-social motivation: A cross-national study. Journal of Cross- Cultural Psychology, 20, 219-243.

[9] Buri, J. R. (1988). Parental authority questionnaire. Journal of Personality and Assessment, 57 (1), 110-119.

[10] Carlo, G., \& Rndall, B. A. (2002). The development of a measure of prosocial behavior for late adolescents. Faculity publication, department of psychology, P70.

[11] Carlo, G., Hausmann, A., Christiansen, S., \& Randall, B. A. (2003). Sociocognitive and Behavioral Correlates of a Measure of Prosocial Tendencies for Adolescents. Faculty Publications, Department of Psychology, P4. 
[12] Eisenberg, N., Carlo, G., Murphy, B., \& Van Court, P. (1995). Prosocial development in late adolescence: A longitudinal study. Child Development, 66, 1179-1, 197

[13] Eisenberg, N., \& Fabes, R. A. (1998). Pro-social development. Handbook of child psychology. Social, emotional, and personality development (pp 701-778). New York, John Wiley and Sons.

[14] Elise, R. D.,\& Kenneth G. R. (2005). The proactive effect of good parenting on adolescents. Division of Adolescent/young Adult Medicine, Children's Hospital, 17, 460-465 Lippincott Williams \& Wilkins, Boston.

[15] Hoffman, M. L. (1982). Development of prosocial motivation: Empathy and guilt. In N. Eisenberg (Ed.), The development of prosocial behavior (pp. 281-313). New York: Academic Press

[16] Hoffman, M. L. (2000). Empathy and moral development: Implications for caring and justice. Cambridge: Cambridge University Press.

[17] Hastings, P. D., Utendale, W., T, \& Sullivan, C. (2007). The socialization of pro-social development. Handbook of Socialization (pp 638-664). Guilford publication.

[18] Krejice, R.; (1970). Determining sample size For Research Activities. Journal of Educational and Psychological Measurement, 30: 607-610.

[19] Lam, C. M. (2012), Azimpour et al., 2012). Pro-social involvement as a positive youth development construct: A conceptual review. The Scientific World Journal, 8, doi: $10.1100 / 2012 / 769158$

[20] Lamborn, S., Mounts, N., Steinberg, L., \& Dornbusch, S. (1991), Santrock, 1993, Patterns of competence and adjustment among adolescents from authoritative, authoritarian, indulgent and neglectful families. Child development. 62 (5), 1049-1065.

[21] Maccoby, E. E., \& Martin, J. (1983). Socialization in the context of the family: Parent child interaction. In E. M. Hetherington (Ed.), P. H. Mussen (Series Ed.), Hand book of child psychology: Socialization, personality, and social development (vol. 4, pp. 1-101). New York: Wiley.
[22] Markos Taddese. (1996). The relationship between parenting styles school performance among high school students in Mekelle. Unpublished M. A Thesis, Addis Ababa university.

[23] McLellan, J. A., \& Youniss, J. (2003). Two systems of youth service: Determinants of voluntary and required youth community service. Journal of Youth and Adolescence, 32 (1), 47-58.

[24] Seleshi, Z., \& Sentayehu T. (1998). Parenting style differences among selected ethnic groups in Ethiopia. Unpublished Research Paper, Forum on Street Children-Ethiopia in Cooperation with Radda Barnen (Swedish Save the Children). Addis Ababa, Ethiopia.

[25] Scott M. H. (2005). The Influence of Parenting Styles on the Development of Moral Judgment in College Level Adolescents, Liberty University.

[26] Tafetu, S. (2007). Factors influencing volunteers helping behavior: case of Red Cross Society Youth Volunteers in Addis Ababa. Unpublished Master's thesis. Addis Ababa University.

[27] Tsehay, D. S., Mulatie, M. W., Sellakumar, G. K., \& Begashaw, G. A. (2014), Abel, 2015, Pro-social behaviors and identity statuses among adolescent students, Addis Ababa Ethiopia. Innovare Journal of Social Sciences, 2 (1), 2347-5544.

[28] Yekoyealem, D. (2005). The relationship between parenting style and identity status of secondary and preparatory school adolescents at Debre Birhan. Unpublished thesis. Addis Ababa.

[29] Zebene. T. (2013) parenting styles in relation to Moral development of adolescents in Debre Birehan secondary and Preparotory schools. Unpublished M. A Thesis, Addis Ababa University.

[30] Zemzem J. (2006). Relationship of parenting styles and academic achievements of adolescents Medical college students in Addis Ababa. Unpublished M. A Thesis, Addis Ababa University 